\title{
Foraging Behaviour of Apis (Megapis) dorsata on Two Mangrove Plant Species
}

\section{Udipta Chakraborti ${ }^{1}$, Bulganin Mitra² ${ }^{2}$ Kakali Bhadra $^{\text {* }}$}

'Department of Zoology, University of Kalyani, Kalyani, 741 235, West Bengal, India.

${ }^{2}$ Ramakrishna Mission Vivekananda College, Rahara, Khardaha, West Bengal, 700 118, India

Key words: Apis dorsata, Handling Time, Mangrove, Visitation Rate, Pollen carrying capacity

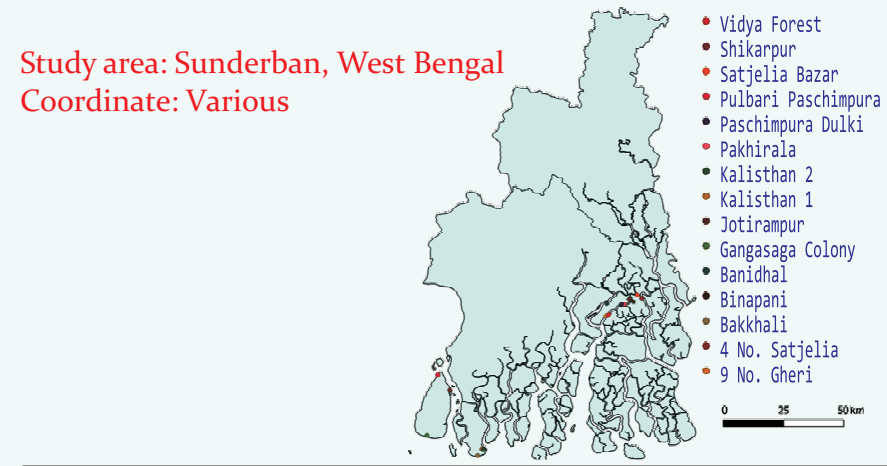

\section{Introduction:}

Mangrove is one of the most ecologically and economically important ecosystem, situated at the convergence of land and sea specially dominated with halophytes and characterized as a fragile but diversified ecosystem; in respect of forest architecture, this ecosystem is quite simpler than rain forest but highly productive (Alongi, 2002; Giri et al., 2010; Mitra et al., 2015; Therttil \& Olakkengil, 2011). Sundarban is the largest mangrove forest around the world. This forest is divided in between two countries; Bangladesh and India. Bangladesh possesses $60 \%$ of mangrove forest of Sudarban where India held the rest.

Foraging activities of flower visitors e.g. visitation rate, handling time, pollen carrying capacity are essential for cross-pollinated plant regarding their reproductive success. With the view of plant reproduction for various angiosperm flowers, plant-pollinator interaction plays a very important role. The diversity and activity of pollinator species mostly depended on various parameters such as flower size, colour, scent, nectar, pollen and many others (Dupont \& Olesen, 2009). Pollination ecology enlightens various aspects of information about the floral structure, the behavioral pattern of interactive animal, the structure

\section{Abstract}

Foraging activities of insect is one of the important phenomena for the reproductive system of the crosspollinated plant. The present study was conducted during the year 2016 to 2018, to explore foraging activities of Apis (Megapis) dorsata on Aegialitis rotundifolia (AR) and Aegiceras corniculatum (AC) mangrove plants from Indian Sundarban. For both the plants, number of A.dorsata was showcasing a positive relationship with bloomed flowers. A.dorsata touched more flowers in one minute (VR) (12.1 \pm 0.74 flowers/minute) on AC plant than on AR, while, the honey bee spent higher time for handling of a single flower (HT) (8.4 \pm 0.88 second/flower) in case of AR than AC. This honey bee species also spent more time to fly in between two consecutive flowers for the plant AR (4.3 \pm 0.56 Seconds) than AC. Furthermore, the pollen-carrying capacity of A.dorsata was higher for the plant AR than the plant AC. This study may indicate that A.dorsata may have an important role as a flower visitor for the reproductive success in both Aegialitis rotundifolia (AR) and Aegiceras corniculatum (AC) in Indian Sundarban.

of plant community, adaptability of visitor and especially the mechanism of pollination (Silberbauer-Gottsberger \& Gottsberger, 1988; Gottsberger, 2012). Mangrove preferably selected with generalize the type of pollination system and this phenomena may happen due to the remote location, less availability pollination recourses and of harsh environmental conditions (Pandit \& Choudhury, 2001). Pandit \& Choudhury (2001) also reported that most of the mangrove plants are not dependent on a particular pollinator type where in some cases, mangroves may be dependent upon some class of pollinators. All the visitors of the angiosperm plant may not be benef iciary regarding the pollination of the plant, such as ant; though they are abundant visitors for some plants, ants are traditionally marked as a poor pollinator (Rostas et al., 2018).

The present communication is conducted in the mangroves of Indian Sundarbans, to study the foraging activities of Apis (Megapis) dorsata Fabricious, 1793 on Aegiceras corniculatum (L.) Blanco (Family: Myrsinaceae) and Aegialitis rotundifolia Roxb. (Family: Plumbaginaceae) plant. Both of the plant genera are showing the characteristic of "Crypto-viviparous" situation (Soloman Raju et al., 2012). A.dorsata was previously reported as a major flower visitor for both the plants (Pandey \& Pandey,

*Corresponding Author:Kakali_bhadra2004@yahoo.com 
2014; Solomon Raju \& Karyamsetty, 2018). Therefore, the study of various foraging activities of this honey bee species on these plants may indicate its' potentiality as a flower visitor as well as a pollinator.

\section{Materials and methods:}

Studied Plant: the present study was conducted on two ecologically important true mangroves viz. Aegiceras corniculatum (AC) and Aegialitis rotundifolia (AR) to determine the ecological role of A.dorsata in their pollination. Very few works have been conducted till now regarding the insect pollination of these plant species from Sundarban mangrove, among them Chakrabarti (1985), Naskar \& Mandal (1999), Bhattacharya et al. (2006) \& Mitra et al. (2015) was notable (Table-1).

Table-1 Morphology of studied mangrove plants

Aegialitis rotundifolia: Small Tree, $\sim 3 \mathrm{~m}$ ht.; Leaf structureRound, broadly ovate or sub orbicular, size -2.5 to $9 \mathrm{~cm} \times 3$ to $9 \mathrm{~cm}$; Flower Colour- White, size- $18 \mathrm{~mm}$ long $11 \mathrm{~mm}$ diameter, 5 sepals, flowering period - Late February to Early April

Aegiceras corniculatum: Small Tree, $\sim 6 \mathrm{~m}$ ht.; Leaf structureOvate oblong, size- 4 to $8 \mathrm{~cm} \times 2$ to $4 \mathrm{~cm}$; Flower Colour- White, size- $17 \mathrm{~mm}$ long $10 \mathrm{~mm}$ diameter, 5 sepals, flowering period - Late February to Early April

Reference: Aluri, 1990a; Aluri, 2013; Aluri \& Karyamsetty, 2018, http://www.bsienvis.nic.in/Database/IndianMangroves_3941.aspx

Study area: the study was performed in the mangrove ecosystem of Sundarban Biosphere Reserve of the district South 24 Paraganas from the state West Bengal, India. Total numbers of five islands namely Gosaba, Satjelia, Bali, Bakkhali and Sagar Island have been selected for performing the study. From these five islands, on the basis of the availability and accessibility of the studied plants, three study areas have been selected from each island for further work (Map). Map is constructed by using QGIS 3.4 Madeira software (http://qgis.osgeo.org).

Sampling technique: three individuals of each plant species have been selected randomly from a marked area of $500 \mathrm{~m}^{2}$ (10m width $\times 50 \mathrm{~m}$ length) in each study area. The study was performed in the time of the flowering period of respective plants during the year 2016 to 2018. Each plant individual was monitored for the time period of 6 am to 6 pm with 2 hours of intervals, thrice in a week. The collection procedure, preservation procedure, setting and pinning procedure was followed by the manual of Zoological Survey of India (Jonathan \& Kulkarni, 1986). For the identification of flower visitors, the specimens were taken to the Zoological Survey of India, Kolkata.

Foraging efficiency of flower visitors: for the maximum time of one minute, an individual flower visitor was monitored continuously for respective plant species. Each observation period was included with, total time spend on flower or flowers by an insect individual (TF; touching or landing on the flower to departure from the flower), total observation time (TT; the time is consisting with the total time spent on flower/flowers and total time of flight between two consecutive flowers of the same plant species) was taken with the help of separate stopwatches. The total number of flowers visited by an insect (here A.dorsata) individual during an observation period was also recorded (NF). Three parameters were analyzed from these data; A) visitation rate (VR; flowers/minute)- average number of flowers visited by an insect individual per unit of time (NF/TT), B) handling time (HT; sec./flower)- average time spending by an insect on a single flower (TF/NF) and C) flight time (FT; sec.)- average Time spent in between the flight of two consecutive flowers while foraging [FT= (TT$\mathrm{TF}$ )/NF] (Herrera, 1989; Meerabai, 2012; Bhowmik et al. , 2018).

Correlation analysis: to analyze the relationship between A.dorsata and bloomed flowers of AC and AR plants, correlation analysis was performed. The number of A.dorsata was counted in one minute of time along with the number of bloomed flowers on a randomly selected branch or inflorescence (as preferable) of the respective plant. A total number of 30 observations have been taken for each plant species for the calculation. Microcal Origin (version 6.o) software and Microsoft Excel 2007 software was used to calculated correlation analysis. The value of $r$ indicates the potentiality of the relationship whether it is strong or weak, $r$ value nearer to 1 leads stronger relationship among A.dorsata and the bloomed flowers of the plant.

Pollen collection and Pollen carrying capacity: for the estimation of pollen carrying capacity, A.dorsata was captured from 8 am to 11 am of the time interval and the pollen was separated by smooth brushing and washing technique. The pollen of corbiculae was separated in the beginning, only the loose pollen attached to the different body parts of A.dorsata was taken for estimation. A total number of 10 individuals were taken for pollen carrying capacity estimation. For the reference of pollen of respective plant species, pollen was directly collected by smashing the mature anthers of the plant on a glass slide and prepared a temporary slide. The pollen was then photographed with the help of phase contrast microscope (Olympus CKX 53 microscope, Magcam MU2A camera) with desirable magnification.

Statistical analysis: BOX plot analysis was performed by using. Microcal Origin (version 6.o) software for exploring the range of VR, HT, FT and pollen carrying capacity of A.dorsata in the studied plants. Chi-square test was performed $(\mathrm{p}<0.05)$ to indicate variation in the pattern of VR and HT of A.dorsata in different time intervals on an average of three years data.

\section{Results:}

Correlation analysis among A.dorsata with bloomed flowers: in the present study, data reveals that the number 
of A.dorsata showed a positive relationship with the bloomed flowers of AC and AR plants. More specifically, AC showed stronger relation with A.dorsata than AR $(\mathrm{r}=0.68, \mathrm{n}=30, \mathrm{p}<0.05$ for $\mathrm{AC} \& \mathrm{r}=0.54, \mathrm{n}=30, \mathrm{p}<0.05$ for $\mathrm{AR})$ (Fig.-1a,b).
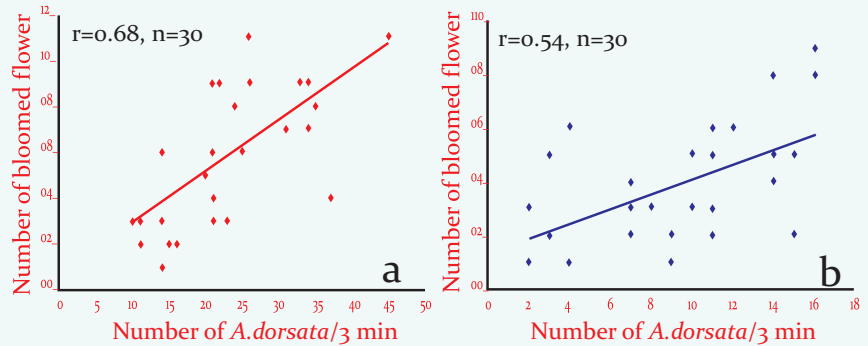

Figure-1: Correlation analysis in between A.dorsata \& bloomed flowers [a] Aegiceras corniculatum [b] Aegialitis rotundifolia

Different foraging activities of A.dorsata on AC and AR plants: VR is one of the most important parameters to determine the efficiency of flower visitor regarding the plant-pollinator relationship. The present study revealed that A.dorsata was showing higher VR in case of AC

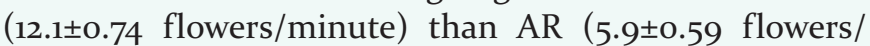
minute) on an average. The estimation of HT is important for the determination of foraging eff iciency. On an average, A.dorsata was with higher HT for AR plant $(8.4 \pm 0.88$ sec./flower) than AC (5.05 $\pm 0.31 \mathrm{sec}$./flower) .

FT is also an essential parameter to denote the pattern of the visit of different insect flower visitor; here, $A$.dorsata

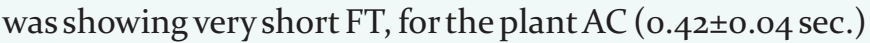
whereas, for plant AR, A.dorsata was showing a comparatively higher in range of FT ( $4.3 \pm 0.56 \mathrm{sec}$.).

Visitation Rate pattern of A.dorsata on AC and AR plants: for both of the plants, the pattern of VR was almost the same among the three years. In both cases, A.dorsata showed peak VR in the time interval of 8 am to $10 \mathrm{am}(\mathrm{VR}=$ $16.9 \pm 0.56$ flowers/min. for $A C \& V R=10.9 \pm 0.81$ flowers/ min. for AR; Average of three years data) and the least VR showed by A.dorsata in the time interval of $2 \mathrm{pm}$ to $4 \mathrm{pm}$ $(\mathrm{VR}=4.1 \pm 0.20$ flowers $/ \mathrm{min}$. for $\mathrm{AC} \& \mathrm{VR}=\mathbf{2 . 4} \pm 0.23$ flowers/min. for AR; Average of three years data) (Fig.-2a \& 3a). Chi-square analysis is showcasing that there was signif icant variation in VR of A.dorsata among the six-time intervals for both of the plants (Table-2)
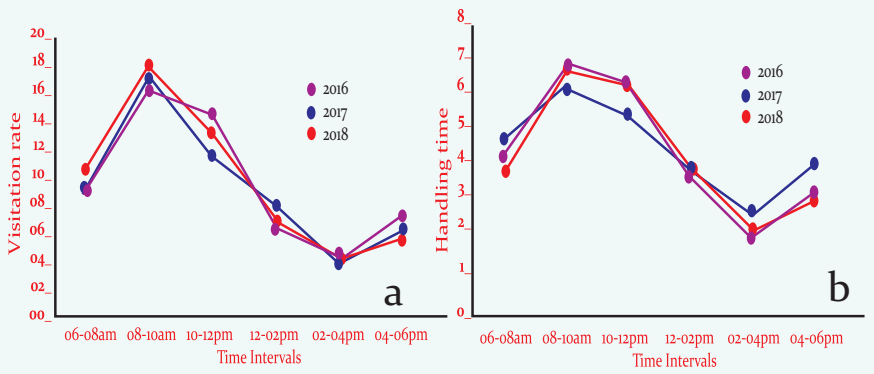

Figure 2: Line graph of foraging activities pattern of A.dorsata on Aegiceras corniculatum [a] Visitation Rate; [b] Handling Time
Table-2 : Chi-square analysis of Visitation rate \& Handling time of $A$. dorsatai among different time intervals. "**” marked value indicates significant variation $(\mathrm{p}<0.05)$

\begin{tabular}{lll}
\hline$\times^{2}$ value & Degree of freedom $(\mathrm{df})$ & $\mathrm{p}$ value \\
\hline 11.8 & Aegiceras corniculatum Visitation Rate (5) & $<0.03^{*}$ \\
2.8 & Aegiceras corniculatum Handling Time (5) & $>0.71$ \\
13.9 & Aegialitis rotundifolia Visitation Rate (5) & $<0.01^{*}$ \\
1.8 & Aegialitis rotundifolia Handling Time (5) & $>0.87$ \\
\hline
\end{tabular}

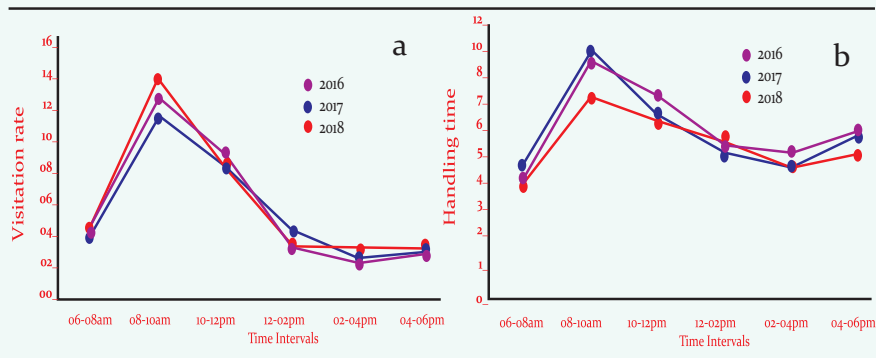

Figure-3: Line graph of foraging activites pattern of A.dorsata on Aegialitis rotundifolia [a] Visitation Rate; [b] Handling Time

Handling Time pattern of A.dorsata on AC and AR plants: for both of the plants, the pattern of HT was almost the same throughout the three years. In both cases, A.dorsata showed the highest HT in the time interval of 8 am to $10 \mathrm{am}(\mathrm{HT}=6.4 \pm 0.14$ sec./flower for $\mathrm{AC} \& \mathrm{HT}$ $=9.9 \pm 0.60 \mathrm{sec}$./flower for AR; Average of three years data) whereas the lowest HT showed in the time interval of $2 \mathrm{pm}$ to $4 \mathrm{pm}(\mathrm{HT}=2.3 \pm 0.17 \mathrm{sec}$. $/$ flower for $\mathrm{AC} \& \mathrm{HT}=5.9 \pm 0.21$ sec./flower for AR; Average of three years data) (Fig.-2b \& 3b). Chi-square analysis demonstrated no significant variation among the HT of A.dorsata in different time intervals for both plants (Table-2).

The pollen-carrying capacity of A.dorsata on AC and AR plants: the analysis of pollen carrying capacity is an essential parameter to determine the plant-insect interaction regarding the pollination of plant and pollinator efficiency. A.dorsata showed higher average pollen carrying capacity for the plant AR (594.1 \pm 89.7 pollen/individual, $\mathrm{n}=10)$ than AC plant $(509 \pm 79$ pollen/individual, $\mathrm{n}=10$ ) (Plate-1a \& b).

\section{Discussion:}

Plant and flower visitor relationship is an essential phenomenon with respect to the reproduction in the plant. Insects play an important role as pollinators for various cross-pollinated plants. The interaction between plant and their pollinator are often considered as mutualistic and tightly coevolved relationship (Huang \& Giray, 2012).

In a plant-pollinator relationship, the foraging parameters like VR, HT, and visitation frequency, of pollinators show an important role regarding the plant reproductive success for the cross-pollinated plants (Artz \& Nault, 2011; Ne'eman et al., 2010). VR of flower visitor depends on various parameters, such as flower structure, colour, size, flower design, the temporal and spatial 


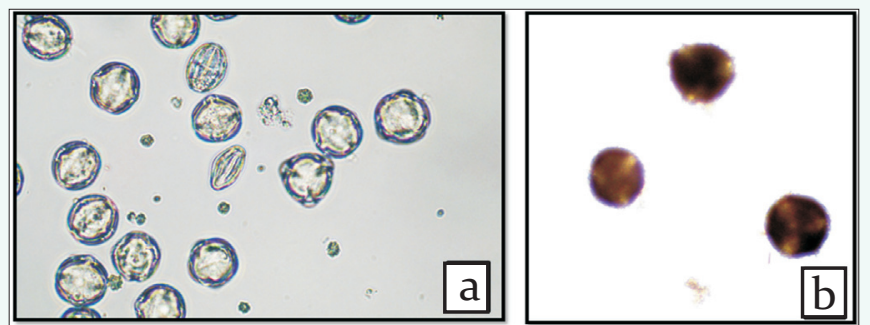

Plate-1: Phase contrast microscopic photograph of pollen [a] A.corniculatum (4oX); [b] A.rotundifolia (10X)

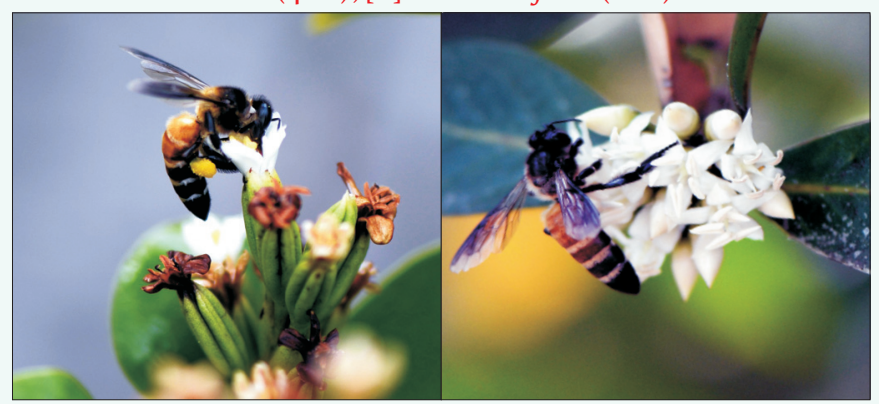

Plate-2: Photograph of A.dorsata on flower [a] Aegialitis rotundifolia; [b] Aegiceras corniculatum

structure of floral display and nectar production. In this present communication, analyses of different foraging activities of A.dorsata help to predict its' importance as an essential flower visitor of studied mangroves. A.dorsata showed higher VR (6.4 to 20 flowers/min.) and lower FT (o.12 to 1.16 seconds) in AC than AR (VR range $=2$ to 15 flowers/min.; FT range $=0.6$ to 13 seconds). This phenomenon may happen due to the completely different floral structure of both the plants (Plate-2). AC offers more flowers in a single inflorescence than AR and the distance between two consecutive flowers AC are far closer than the distance of two consecutive flowers of AR. For each of the plants, A.dorsata showed the same VR and HT pattern among the three years. In which, the time interval of 8 am to 10 am held the peak VR and 2 pm to 4 pm showed the least for both the plants. In the time interval of $8 \mathrm{am}$ to $10 \mathrm{am}$, A.dorsata spent the highest HT, while the lowest for the time interval of $2 \mathrm{pm}$ to $4 \mathrm{pm}$ on both plants. Chi-square analysis shows significant variation in VR among different time intervals for both plants but not in HT for both cases.

Anthesis of AC was reported during 0500 hrs to 1900 hrs and maximum completion occurs during the forenoon period and the stigma receptivity is high during the morning and evening time period. It was also reported that the nectar of this plant is composed of different sugars such as fructose, galactose etc. also with amino acids such as, butyric acid and aspartic acid. The availability of nectar of this plant is high during the morning and evening period while in the noon period the nectar availability is lower in range (Pandey \& Pandey, 2014). AR was reported with anthesis in the morning and the odourless flower denotes that this plant is meant to be pollinated in the daytime. In the nectar of this plant, both essential and non essential amino acids such as lysine, tryptophan, phenylalanine, valine, threonine, and histidine is present and some of them are required for honey bees, because of that reason this plant may be better inclined for bee pollination or they show better melittophilous pollination (Solomon Raju \& Karyametty, 2018; DeGroot, 1953). A.dorsata was showing signif icantly positive relation with the bloomed flowers of each of the plants where it showed a stronger relation with AC than AR. On the basis of pollen carrying capacity, A.dorsata clearly carrying a higher range of pollen (119 to 937 pollen/individuals) for AR plant, while the range was slightly lower in case of AC (117 to 866 pollen/individuals). All these analyses are likely to be indicating that the foraging pattern and foraging activities of this honey bee has an important role in the pollination of AC and AR (Fig.6). All over the world Mangrove ecosystem is considered as a threatened one (Alongi, 2002). Sundarban Mangrove forest of Sundarban is also troubled with a lot of natural catastrophes and various anthropogenic threats (Mahadevia \& Vikas, 2012). It was reported that seven mangroves are threatened and need to be conserved among the common mangroves of Sundarban and A.corniculatum (AC) is one of them. Barik \& Chowdhury (2014) reported that A.rotundifolia (AR) is a near threatened species in the mangrove ecosystem.

Conclusively, qualitative and quantitative analyses may indicate that various foraging activities such as VR, HT, FT and Pollen carrying capacity of $A$.dorsata serves an essential role in the reproduction of both the plants. The present study also demonstrates that foraging pattern of $A$.dorsata may have a prominent positive relationship with the reproductive activities of these two mangroves, which indicates that, A.dorsata may have an ability for being a potential flower visitor for pollination of these two mangroves. Therefore, conservation of A.dorsata is highly recommended for ensuring the cross-pollination reproductive success of A.corniculatum (AC) and A.rotundifolia (AR) plant.
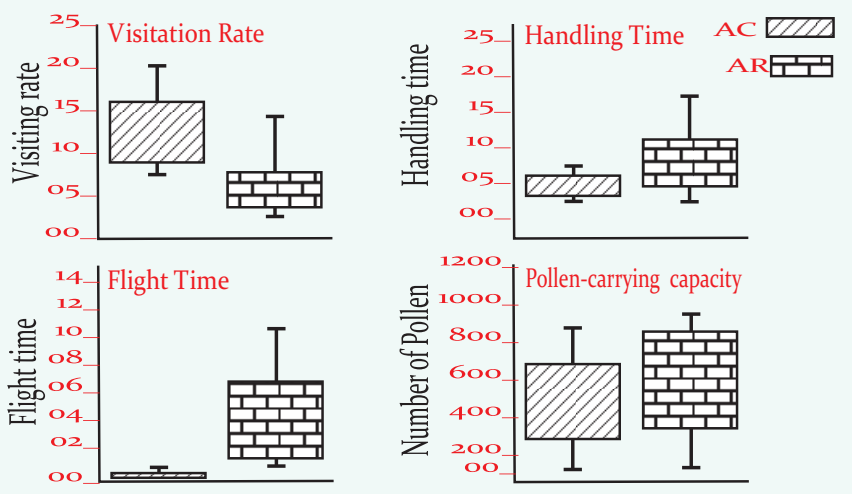

Figure-6: Box plot analysis of different foraging activities of A.dorsata on A.corniculatum \& A.rotundifolia

Acknowledgements:

KB is indebted to the Department of Science \& Technology, W.B., 
Govt. of India (DST, W.B.) for the financial support (Ref. No. $865 / \mathrm{ST} / \mathrm{P} / \mathrm{S} \& \mathrm{~T} / \mathrm{1G}-1 / 2015)$. UC is supported by grant from DST, West Bengal. Authors are also thankful to PRG, University of Kalyani, 2017-18 for their partial financial support. Authors are grateful to the Director of Zoological Survey of India, Kolkata, for his necessary support. Authors are also grateful to Prof. Animesh Kumar Datta, Dept. of Botany, University of Kalyani, for his untiring support in statistical analysis. Authors are also grateful to Dr. Arunima Biswas, Assista. Prof., Dept. of Zoology, University of Kalyani, for allowing authors to use phase contrast microscope.

\section{References:}

Alongi, D.M. (2002): Present state and future of the world's mangrove forests. Environl. Conserv., 29(3):331-349. .

Aluri, J.S.R.(1990): Observation on the floral biology of certain mangroves. Proc. Ind.Nat.Sci.Acad., B56(4):367-374.

Aluri, J.S.R. (2013): Reproductive ecology of mangrove flora: Conservation and management. Transylv. Rev. Syst. Ecol. Res., 15(2): 133-184.

Aluri, J.S.R. \& Karyamsetty, H.J. (2018): Reproductive ecology of Aegialitis rotundifolia Roxb., a crypto-viviparous mangrove plant species in Krishna Mangrove Forest, Andra Pradesh. Transylv. Rev. System. Ecol. Res., 20(1):17-30.

Artz, D.R. \& Nault, B.A. (2011): Performance of Apis mellifera, Bombus impatiens and Peponapis pruinosa (Hymeoptera: Apidae) as pollinators of Pumpkin. J. Econ. Entomol., 104(4):1153-1161.

Barik, J. \& Chowdhury, S. (2014): True mangrove species of Sundarbans delta, West Bengal Eastern India. Check List, 10(2):329-334.

Bhattacharya, K., Majumdar, M. R. \& Bhattacharya, S.G. (2006): A Textbook of Palynology (Basic and Applied). Pub. by: New Central BookAgency (P) Ltd., Kolkata. P. 352.

Bhowmik, B., Chakraborti, U. \& Bhadra, K. (2018): Ecological Role of the Insect Pollinators in Seed Yield of Cross Pollinated Sesamum indicum from West Bengal, India. Amibient Sci., 5(2):34-39.

Chakrabarty, K. (1985): Sundarbans (India) honey and Mangrove Swamps. L. Bombay Nat. Hist. Soc., 84(1):133-137.

De Groot, A.P. (1953): Protein and amino acid requirements of the honey bee (Apis mellifica L.). Physiol. Compar. Oecol., 3:197285 .

Dupont, Y.L. \& Olesen, J.M. (2009): Ecological modules and roles of species in healthland plant-insect flower visitor networks. J.Anim. Ecol., 78(2):346-353.

Giri, C., Ochieng, E., Tieszen, L.L., Zhu, Z., Singh, A., Loveland, T., Masek, J. \& Duke, N. (2010): Status and distribution of mangrove forests of the world using earth observation satellite data. Global Ecol. Biogeogr., 20(1):154-159.
Gottsberger, G. (2012): How diverse are Annonaceae with regard to pollination? Bot. J. Linnean Soc., 169(1):245-261.

Herra, C.M. (1989): Pollinator abundance, morphology, and flower visitation rate: Analysis of the quantity component in a plant-pollinator system.Oecologia, 8o(2):241-248.

Huang, Z.Y. \& Giray, T. (2012): Factors affecting pollinators and pollination. Psyche, 3:302-409,

Jonathan, J.K. \& Kulkarni, P.P. (1986): Manual: Collection, Preservation and Identification of Insects and Mites of Economic Importance, in Tikader B.K. (ed. ). Pub. by: Zoological Survey of India. P. 322.

Mahadevia, K. \& Vikas, M. (2012): Climate change-Impact on the Sundarbans: A case study. Int. Sci. J. Environ. Sci., Online:715.

Meerabai, G. (2012): Visitation rate, effectives and efficiency of pollinators to Cadaba fruiticosa(Linn.) Druce. Bioscan, $7(3): 483-485$.

Mitra, B., Biswas, O., Roy, S. \& Chakraborti, U. (2015): Pollinators of mangrove in the perspective of Indian Sundarbans. ENVIS newslett., 21:6-11.

Naskar K. \& Mandal R. (1999): Ecology and Biodiversity of Indian Mangroves, Part I, Global Status. Pub. by: Daya Publishing House, New Delhi, India. P. 783.

Ne'eman, G., Jurgens, A., Newstrom-Lloyd, L., Potts, S. \& Dafni, A. (2009): A framework for comparing pollinator performance: effectiveness and efficiency. Biol. Rev. Camb. Philos. Soc., $85(3): 435-451$.

Pandit, S. \& Choudhury, B.C. (2001): Factors affecting pollinator visitation and reproductive success in Sonneratia caseolaris and Aegiceras corniculatumin a mangrove forest in India. L. Trop. Ecol.,17(3):431-447.

Pandey, R. \& Pandey, C.N.(2014): Reproductive strategy of Aegiceras corniculatum L. (Blanco.)-A Mangrove species, in MNP\&S, Gujarat, India. J. Plant Stud., 3(1):35-55.

Rostas, M., bollmann, F., Saville, D. \& Riedel, M.(2018): Ants contribute to pollination but not to reproduction in a rare calcareous grassland forb. Peer J. eCollection 2018

Silberbauer-Gottsberger, I. \& Gottsberger, G. (1988): A polinizacao de plantas do cerrado. Rev.Brasil.Biol., 48(4):651663.

Solomon Raju, A.J., SubbaRao, R.V., Kumar, R. \& Rama Mohan, S. (2012): Pollination biology of the crypto-viviparous AvicenniaSpecies (Avicenniaceae). L. Threat. Taxa, 4(15):3377-3389.

Therattil, J.J. \& Olakkengil, J.L. (2011): Diversity and distribution of destructive insects in Chettuvai mangroves, Kerala, India. Millennium Zool., 12(1):35-37. 